\title{
Commentary beyond the Codex: Hypertext and the Art of Biblical Commentary
}

\author{
Tim Bulkeley (University of Auckland)
}

ABSTRACT:

\section{INTRODUCTION}

In a number of places one hears biblical scholars dream of a new kind of commentary, a commentary with hypertext links and multimedia elements. ${ }^{1}$ This paper, though it ends with such dreams, is based on the experience of an ongoing project, begun in 1995, to discover the opportunities and constraints on such a commentary (Postmodern Bible Amos). ${ }^{2}$ It explores the nature of hypermedia commentary writing, in the light of this research.

Biblical commentary fulfils the three requirements for material that is suited to hypertext delivery:

"1. large body of information able to be presented in fragments

2. fragments relate to one another

3. user needs only a small proportion of fragments at any one time." (Shneidermann 1989, 115-131)

1 This dream was expressed in different forms more than once at the AIBI conference at which this paper was presented.

2 The working materials of the Amos project so far are all available on the web at Tim Bulkeley Postmodern Bible - Amos, http://www.bible.gen.nz. 


\section{DEFINITION}

Hypertext is simply a non-linear way of presenting information. Rather than reading or learning about things in the order that an author, or editor, or publisher sets out for us, readers of hypertext may follow their own path, create their own order-their own meaning out (sic) the material. ${ }^{3}$

Of course this is basically Ted Nelson's classic: Hypertext is "nonsequential writing - text that branches and allows choices to the reader, best read at an interactive screen (Nelson:1992:0/2)". Yet by focussing on the user's perspective the first definition is more active and engaging.

Biblical scholars (the writers of commentaries) work with texts; most are bibliophiles. This experience and vision of the world are poor preparation for hypertextuality

The second section of the paper "Constraints of Hypermedia: Learning to Write" will explore ways in which hypertext lexias ${ }^{4}$ should be written differently from conventional text. Meanwhile the first section will briefly rehearse some of the opportunities this medium opens and so is titled:

\section{OPPORTUNITIES OF HYPERMEDIA: USING TO LEARN}

Hypertext opens new possibilities for the craft of biblical commentary writing. By its structure as interlinked lexias, and by its nature as electronic text, hypertext offers multiple paths through the material. It also permits the easy and cheap inclusion of rich media (notably sound

3 Kimberly Amaral "Hypertext and writing: An overview of the hypertext medium" http://www.umassd.edu/Public/People/KAmaral/Thesis/ hypertext.html (downloaded 30/ 06/00).

4 The term is adapted from Roland Barthes, and has been commonly (following Landow 1993:52) used to speak of the textual units within a hypertext. 
and colour pictures). These two features make possible the production of one text for a variety of users.

\subsection{Paths}

Hypertext is accomplished by links between lexias. As has been often noted the fact that each user makes their own selection of material and also determines the sequence in which it is viewed changes the relation between "author" and "reader". 5 This is true even of what Michael Joyce distinguishes as "exploratory hypertexts" (Joyce 1988: 10-14, 37-42.) (those which the user cannot add to or alter, like Amos, though it is much more obviously true for constructive hypertexts).

Amos with its multiple windows allowing exploration of the words of the biblical text, or items suggested by the comment, offers dozens of paths from every screen. ${ }^{6}$ Even the simplest hypertexts can present a vast array of possible choices, and their order depends on the reader, so a hypertext can never be adequately represented in print. ${ }^{7}$

With its webs of linked lexias, its network of alternate routes (as opposed to print's fixed unidirectional page-turning) hypertext presents a radically divergent technology, interactive and polyvocal, favoring a plurality of discourses over definitive

5 These terms are not appropriate to hypertexts; I will use "writer" and "user" which while still problematic are more appropriate. "Writer" does not so evidently imply authority and users of a hypertext only "read" the textual portions images and sounds are not "read" in the usual sense, but both they and the text are "used".

6 http://www.bible.gen.nz/000paper.htm (downloaded 30/06/00).

7 Michael Joyce "Of Two Minds: Hypertext, Pedagogy and Poetics", http://iberia.vassar.edu/ mijoyce/What_s_hypertext.html (downloaded 30/06/00). 
utterance and freeing the reader from domination by the author (Coover 1992).

For commentary writing this potentially offers freedom from the need to be polemic and combatitive, or even competitive. The codex through its intimate association with an author requires "authority". The publisher through their necessary association with the marketplace requires profit. The technology of print has therefore tended to produce commentaries which must each proclaim the authority of its author and the distinctive and competitive nature of its contents, in order to rival other commentaries.

The cheap, aggregative nature of electronic text, together with the ease of collaboration in this medium, permits or even encourages the development of collaborative even "traditional" commentaries. Traditional in the sense of material which changes and adapts slowly through consensual adoption rather than through combat and victory.

The Amos commentary does not illustrate this in its first stage. However, the second stage, which will present material (pictures, statistics, poems, news items etc.) which suggest ways for the user to relate the biblical text to the contemporary world should be a collaborative and growing production, less governed by the dead habits of an old bibliophile.

\subsection{Media}

The variety of media inherent in an electronic "text" offers commentarywriters opportunities to enrich their work. Colour pictures explain much more clearly the location of events and the nature of objects referred to in 
the text. ${ }^{8}$ Sound files illustrate more directly the joyous play of sound and meaning that delighted the ancient Hebrew writers and their hearers, ${ }^{9}$ better than the most ingenious typography. ${ }^{10}$

\subsection{Levels}

A text must assume a certain level of knowledge in its reader. If the author assesses this level too high the text is incomprehensible. If they write for absolute beginners the text becomes insufferably boring for the knowledgeable. A hypertext, by permitting explanatory links (the "Bible Dictionary" and "Glossary" material in Amos for example), allows its writers to open the work to a much wider range of users.

\section{CONSTRAINTS OF HYPERMEDIA: LEARNING TO WRITE}

The nature of hypertext, as interlinked lexias displayed on a screen, while it liberates the user, imposes constraints on the writer.

In its origins the Amos commentary was a bibliophile's hypertext, a series of scrolls interlinked by anchors and jumps. I am currently in process of adapting the material into smaller more focussed lexias. Compare the treatment of the words hyh (part of a scroll treating all words beginning with $h$ ) and $r \# \$$ ) (whose lexia is a file to itself) in Am 1:1. ${ }^{11}$

Until screen technology improves greatly, poor resolution and so readability by comparison with print suggest that writing must be more concise, but at a deeper level bifurcating multibranched text poses problems for comprehension. Each lexia must be comprehensible either

8 As http://www.bible.gen.nz/amos/pics/danbricks.jpg (downloaded 30/06/00) might clarify a discussion of building materials, ashlar and uncut stone.

9 For, though written, biblical texts are, in many ways, more oral than literate.

10 Cf http://www.bible.gen.nz/amos/literat.htm\#9_14 (downloaded 30/06/00) click the Hebrew text.

11 Since the paper was delivered this has now largely been done. 
on its own, or aided by explanatory material one jump away. Unlike a print text there is no material that a hypertext writer can assume their reader will have consulted on the way to the current lexia.

The Amos commentary seeks to some extent to circumvent this limitation through the use of frames, which provide context. For example, the biblical text is viewable by the user at the same time as comment or discussion of the words used. However, frames are anathema to hypertext purists. User feedback on Amos is mixed, with far more appreciating frames than resenting them.

\subsection{Readability: Nielsen's usability ratings}

Jakob Nielsen has conducted extensive usability studies on hypertexts, and in particular on web texts. Already by 1998 certain conclusions regarding writing for hypertext were clear. The two that impact most on commentary writing are related:

"users do not read on the Web; instead they scan the pages, trying to pick out a few sentences or even parts of sentences to get the information they want

users do not like long, scrolling pages: they prefer the text to be short and to the point." 12

John Morkes and Jakob Nielsen studied 81 users reading Web pages. Two studies produced qualitative data suggesting how users read, and their likes and dislikes. The third study aimed to measure the benefit

12 Nielsen, J. "Be succinct! (Writing for the Web)" http://www.useit.com/alertbox/9703b.html (downloaded 30/06/00). 
of adapting material to the writing styles suggested by the other studies. $^{13}$

Several conclusions from their studies are particularly relevant to the art of writing hypertext commentaries:

\subsubsection{Users want to get Information Fast}

This seems obvious; yet writers nurtured in the age of the codex unconsciously assume their users will operate at the leisurely speed of print. This risks undermining the hypertext enterprise.

The other three largely follow from this first, particularly as it interacts with the limitations of a screen.

\subsubsection{Text should be Scannable}

Morkes and Nielsen write that "Scanning can save users time... 15 participants always approached unfamiliar Web text by trying to scan it before reading it. Only 3 participants started reading text word by word... Elements that enhance scanning include headings, large type, bold text, highlighted text, bulleted lists, graphics, captions, topic sentences, and tables of contents." ${ }^{14}$ This list concerns the layout more than the writing, but already (e.g. bulleted lists) points away from the discursive model of print commentaries.

\subsubsection{Text should be Concise}

One popular guide to effective writing for the web suggests that a web page should use $50 \%$ or less of the words that an equivalent paper document (McAlpine 1999:91).

13 John Morkes and Jakob Nielsen "Concise, SCANNABLE, and Objective: How to Write for the Web" http://www.useit.com/alertbox/writing.html (downloaded 30/06/00). 
Morkes and Nielsen found that simply reducing the number of words (to about half) increased usability by $58 \%$ for their sample text. ${ }^{15}$

\subsubsection{Users like Summaries and the Inverted Pyramid Style} Writing for hypertext reverses the norms of $20^{\text {th }}$ century academic style. Nielsen confesses: "One of the occupational hazards of getting a Ph.D. is a distinct predilection for the traditional pyramid style of exposition. I normally write the way I was trained to write: starting with the foundation and gradually building to the conclusion." ${ }^{16}$ Since users of hypertexts do not like to scroll, and have short attention spans, the journalistic "inverted pyramid" is more appropriate.

As McAlpine (op.cit. 98) advises:

"Traditionally, people scan English language documents by reading the first few words of each paragraph. For this reason, put only one idea in each paragraph. And put the main idea right up front, in the first few words.... Never tease people and force them to guess your point."

The linking capability of hypertext leads to the use of summaries, backed up by fuller discussion in another lexia linked from the first. In an extreme case this can continue to at least four levels: from heading to summary to full discussion to background information. Footnotes are the nearest traditional academic writing has come to this practice.

\subsection{Navigation}

How one communicates to the user the options and information available to them is one of the biggest issues before writers of hypertexts. For a

15 John Morkes and Jakob Nielsen "Reading on the Web (Alertbox October 1997)" http://www.useit.com/alertbox/9710a.html (downloaded 30/06/00).

16 Jakob Neilsen "Inverted Pyramids in Cyberspace (Alertbox June 1996)" http://www.useit.com/alertbox/9606.html (downloaded 30/06/00). 
codex the navigation options are few and well understood. Sequential reading is always possible. Tables of contents and indices (as well as occasionally marginal or footnote links - found more often in textbooks e.g. Rendtorff's Introduction - than commentaries) begin to turn a codex into a primitive hypertext. Tables of contents offer a broad but imprecise route to different information. They are not sensitive to the reader's context. Indices offer more precise, but still context insensitive links. Marginal and footnote links do relate to the reader's context.

This recognition of the quasi-hypertext features of codex based commentaries suggest three complementary possibilities for navigation within a hypertext commentary.

\subsection{Text}

The user of a commentary must be able to navigate the text. Ideally for a biblical commentary both in the original language and in translation (for the Hebrew Scriptures the LXX would be useful too). For the Amos project currently only an English translation is available (made by the writer, to avoid copyright problems, and afford a highly literal rendering as a basis for links to word studies).

Where the extra-textual information provided relates directly to particular passages, the writer will need to choose whether moving through the text also changes the lexia shown in the commentary window. This would maintain the intuitive link between commentary and text but introduces other problems, for example when a user studying a particular passage wishes to consult other texts. The two windows are therefore independently navigable in Amos.

17 Rolf Rendtorff The Old Testament: An Introduction London: SCM, 1985 cf. however Walter Brueggemann 1 \& 2 Kings: A Commentary (Smyth \& Helwys Bible commentary ; 8) Macon: Smyth \& Helwys, 2000. 


\subsection{Web or Hierarchical Navigation of Background Material}

One sort of link to background information will naturally occur within lexia. So when "Tekoa" is mentioned in the "notes on 1:1" a link is provided to the lexia about Kirbet Taqu ${ }^{\prime} .{ }^{18}$ Likewise words or phrases that may be unfamiliar to some of the potential users can link to explanations. These links form a web, in many ways similar to the familiar structures of the WWW. Their use is familiar and they provide already a huge number of possible "routes" through the material.

However, such "built in" links do not permit a user to find material that they judge might be useful or relevant if the writer has not foreseen the need. The addition of a hierarchical menu can provide such freedom. Where such a "table of contents" is provided it will be most useful if it works like an expanding outliner (Nielsen 1995:287-288). Such a menu is currently being prepared for Amos.

The main difficulty with each of these approaches to navigation is screen space. The best way to deal with this problem would be opening new windows "above" the existing one. However HTML does not easily permit one to make such windows stay "on top", and this approach, in that format, would risk some users clicking on the main window and so sending the new window to the "bottom", and thus opening large numbers of windows. ${ }^{19}$

\subsection{Bibliography}

The nature of the bibliography provided with such a hypertext raises some questions, in particular of extent and bias.

\subsubsection{Extent}

18 http://www.bible.gen.nz/000paper.htm (downloaded 30/06/00).

19 In August 2001 some Javascript means to oversome these shortcomings are being explored. 
Evidently works cited must be indicated, but how far in an electronic text is it useful to refer to other printed material?

Equally, one could suggest useful sites on the web, though this raises two problems.

- If the commentary is made available on $\mathrm{CD}$, which is desirable until high bandwidth is widely available at low cost, offline users will be frustrated by links to online material.

- Web sites, even those of high academic value change their URLs (not least when their custodians change jobs). The work of maintaining a large list of links up to date is not insignificant. If a hypertext commentary is to maintain links to external resources then it either becomes an ongoing task (unlike the writing of a codex which can be "finished", and whose author can move on to other projects), or it needs an institutional approach to maintenance.

4.5.2 Bias (value vs. accessibility)

Already in the paragraph above I have suggested that the issues of accessibility and value may require some trade-off for a hypertext bibliography. At present a high proportion of the most valuable resources for the users of a hypertext commentary are print works. But print cannot be hyperlinked, and so reference to these works undermines some of the convenience of a hypertext.

On the other hand works on the WWW are easily accessible for most users, and so convenient. However, many are of dubious origin and 
value. Should one link to a resource that provides useful and interesting images, but which may have misleading associated text?

\section{CONCLUSIONS: COMMENTARIES FOR A NEW MEDIUM}

\subsection{Writing New}

\subsubsection{Scannable Writing}

When I began Amos (in 1995), I believed that writing for screen merely meant brevity. Now it is clear that usual patterns of academic writing need to be turned on their head. Brief, bulleted, scannable, inverse pyramid text will work differently from print commentary. The inverse pyramid structure raises unresolved issues most strongly, particularly of bias. The need for bulleted, brief and scannable text may pose fewer problems for commentary writing, they may even help avoid the verbosity of some current works! However, if one accepts the injunction to start from the "main point", how does one allow the user to make up their own mind?

\subsubsection{Multimedia Elements}

With the introduction of multimedia as central to commentary, the availability and choice of media (especially pictures) becomes vital part of "writing". Copyright issues here as elsewhere in electronic media become problematic.

\subsubsection{Open Access}

The possibility of writing for a range of levels of knowledge could result in merging the traditionally different genres of "lay" and scholarly commentaries. Lay commentaries would gain exegetical rigor and perhaps scholarly ones will regain spiritual life that they have sometimes lacked.

\subsection{Working Different}




\subsubsection{Co-operation?}

Our current training and academic structures are only beginning to adapt to the far greater possibilities of co-operation opened by electronic media. But print works like The Postmodern Bible book ${ }^{20}$ and some of its reviews suggest that this may change. Certainly the scale of the Amos project suggests that teamwork would be desirable.

\subsubsection{Commentary as Cathedral}

Scale and the inherently fluid nature of the medium both suggest that electronic commentaries may never be finished. Perhaps like the great European cathedrals commentaries will become the product of generations of scholars, continually being extended and adapted to changing cultural currents.

\section{NEW DIRECTION}

This last section, although it falls within the "conclusions", introduces new material, only referred to in passing above because, like the conclusions, and unlike the body of the paper it relates to future developments rather than past experience.

\subsection{Text to World}

Stage two of Amos will be the production of a collection of material that suggests connections between the biblical text and the contemporary world. Originally back in 1995 it was envisaged that this "foreground" material would grow alongside the "background" commentary. The scale of the task, and my desire that the selection of this material be done by more than one person, mean this has not happened.

20 The Bible and Culture Collective, The Postmodern Bible New Haven: Yale University Press, 1995 (the two projects were named independently at a similar period though with different underlying rationales). 
In this second phase I envisage groups studying a passage and brainstorming ideas for images, statistics and other material that suggest such links. This corpus will also be enhanced by suggestions from online users, to produce a growing (and perhaps rolling) corpus of links.

Traditionally only "devotional" commentaries have tried to move significantly in this direction. But they have tended to be one track and to define a "right way" for their readers to make these connections, and so have been (in a sense) sectarian. The Interpretation series is perhaps a notable exception.

\subsection{Without Prejudice}

The use of a corpus of material of the sort envisaged, and its nomination by varied groups, together with the open-ended nature of the "meaning" of a text-picture gestalt should ensure that this "foreground" section of Amos is non-sectarian.

\subsection{Postmodern Bible}

The Amos project acquired near its beginning in 1995 the name Postmodern Bible Commentary. Till now this has been as misleading as the names "multimedia Bible" and "hypertext Bible" have usually been! However, the open-ended intertextual character of this second stage of the project may at last justify the name!

\section{BIBLIOGRAPHY}

Amaral, K (downloaded 30/06/00). Hypertext and writing: An overview of the hypertext medium; http://www.umassd.edu/Public/People/Kamaral /Thesis/ hypertext.html.

Barrett, E (ed) 1989. The Society of Text. Cambridge MA: MIT.

Birkerts, S 1994. The Guttenberg Elegies: The Fate of Reading in an Electronic Age. New York: Fawcett Columbine. 
Bulkeley, T 1995-2001. Postmodern Bible - Amos. http://www.bible.gen.nz.

Coover; R 1992. The End of Books. New York Times Book Review June 21, in: Birkerts (1994, 153).

Joyce, M 1988. Siren Shapes: Exploratory and Constructive Hypertexts. Academic Computing 3 (1988) 10-14, 37-42.

Joyce, M (downloaded 30/06/00). Of Two Minds: Hypertext, Pedagogy and Poetics. http://iberia.vassar.edu/ mijoyce/What_s_hypertext.html.

Landow, G 1993. Hypertext in Hypertext. Baltimore: Johns Hopkins UP. McAlpine, R 1999. Web Word Wizardry. Wellington: Corporate Communications.

Morkes, J and Nielsen, J (downloaded 30/06/00). Concise, SCANNABLE, and Objective: How to Write for the Web. http://www.useit.com/alertbox/writing.html.

Morkes, J and Nielsen, J (downloaded 30/06/00). Reading on the Web (Alertbox October 1997). http://www.useit.com/alertbox /9710a.html.

Nelson, T H 1992. Literary Machines 93.1. Sausalito, CA: Mindful Press, 1992, 0/2.

Neilsen, J 1995. Multimedia and Hypertext: The Internet and Beyond. Boston: Academic.

Nielsen, J (downloaded 30/06/00). Be succinct! (Writing for the Web) http://www.useit.com/alertbox/9703b.html.

Neilsen, J (downloaded 30/06/00). Inverted Pyramids in Cyberspace (Alertbox June 1996). http://www.useit.com/alertbox/9606.html.

Shneiderman, B 1989. Reflections on authoring, editing and managing hypertext, in: Barrett (ed), 115-131.

The Bible and Culture Collective, The Postmodern Bible New Haven: Yale University Press, 1995. 